\title{
Principios de intervención biopsicosocial en la crisis del ébola
}

\section{Principles of biopsychosocial intervention in the ebola crisis}

\author{
Manuel Moyano ${ }^{1}$ y Humberto Manuel Trujillo ${ }^{2}$ \\ ${ }^{1}$ Departamento de Psicología, Universidad de Córdoba, España. \\ ${ }^{2}$ Departamento de Metodología de las Ciencias del Comportamiento, Facultad de Psicología, Universidad de Granada, España.
}

Disponible online 31 de agosto de 2016

\begin{abstract}
En agosto de 2014 la Organización Mundial de la Salud (OMS) declaró a la enfermedad por el virus del ébola (EVE) como una emergencia sanitaria pública de carácter internacional. Aunque esta epidemia venía siendo una realidad en diferentes países africanos, en octubre del mismo año se prestó especial atención a la gestión y comunicación de lo que fue el primer caso de contagio en Europa; concretamente, en España. En el presente artículo se realiza una propuesta de siete principios de intervención biopsicosocial que deberían concebirse como un marco útil desde un punto de vista de la gestión de la salud pública y las emergencias sanitarias. Son los siguientes: (1) riesgo real y riesgo percibido no son equivalentes; (2) contención, juicio y prudencia en la comunicación; (3) el todo es más que la suma de las partes; (4) pensamiento divergente para anticiparnos; (5) formación técnica (y psicológica) para los profesionales; (6) asistencia psicológica a profesionales y víctimas; y, por último, (7) arquitectura de una sociedad resiliente.
\end{abstract}

Palabras clave: intervención biopsicosocial; crisis; ébola; riesgo; salud pública.

In August 2014, World Health Organization (WHO) declared the ebola virus disease (EVD) as a public health emergency of international concern. Although this epidemic was already a reality in different African countries, in October of the same year, special attention was paid to the management and communication of the first case of contagion in Europe; specifically, in Spain. This paper provides a proposal of seven principles of biopsychosocial intervention which should be conceived as a useful framework from a point of view of the management of public health and medical emergencies. They are as follow: (1) real and perceived risk are not equivalent; (2) containment, judgment and prudence in communication; (3) the whole is more than the sum of its parts; (4) divergent thinking to anticipate; (5) technical (and psychological) training for professionals; (6) psychological assistance to professionals and victims; and, finally, (7) architecture of a resilient society.

Key words: biopsychosocial intervention; ebola; emergency, risk; public health.

Correspondencia: Manuel Moyano Pacheco. Departamento de Psicología. Facultad de Ciencias de la Educación (Universidad de Córdoba). C/ San Alberto Magno s/n. 14041 Córdoba (España).E-mail: mmoyano@uco.es. E-mail del coautor Humberto M. Trujillo: humberto@ugr.es 
En agosto de 2014 la Organización Mundial de la Salud (OMS) declaró a la enfermedad por el virus del ébola (EVE) como una emergencia sanitaria pública de carácter internacional. De acuerdo con la OMS (OMS, 2014), en relación al virus, podemos decir que: (1) causa en el ser humano la enfermedad homónima (antes conocida como fiebre hemorrágica del ébola); (2) sus brotes tienen una tasa de letalidad que puede llegar al 90\%; (3) dichos brotes se están produciendo, a día de hoy, principalmente en aldeas remotas de África central y occidental, cerca de la selva tropical; (4) se propaga en las poblaciones humanas por transmisión "persona a persona"; (5) se considera que los huéspedes naturales son los murciélagos frugívoros de la familia Pteropodidae; y, (6) actualmente, es necesario seguir avanzando en relación a las evidencias empíricas sobre la efectividad de las vacunas experimentales disponibles. Aunque desde hace meses esta epidemia venía siendo una realidad en diferentes países africanos, en octubre de 2014 prestamos especial atención a la gestión y la comunicación de lo que fue el primer caso de contagio en Europa; más concretamente, en nuestro Estado. Esta crisis sanitaria mantuvo en vilo a decisores políticos, profesionales sanitarios y a la sociedad en general. Y lo acontecido aquellos días permite realizar un análisis de urgencia sobre algunos aspectos con fundamentos e implicaciones biopsicosociales. En el presente artículo se realiza una propuesta de siete principios de intervención biopsicosocial en el abordaje de crisis similares que deberían concebirse como un marco útil desde un punto de vista de la salud pública y las emergencias sanitarias, y con implicaciones a nivel estratégico, táctico y operativo. Son los siguientes: (1) riesgo real y riesgo percibido no son equivalentes; (2) contención, juicio y prudencia en la comunicación; (3) el todo es más que la suma de las partes; (4) pensamiento divergente para anticiparnos; (5) formación técnica (y psicológica) para los profesionales; (6) asistencia psicológica a profesionales y víctimas; y, por último, (7) arquitectura de una sociedad resiliente.

Primero. Riesgo real y riesgo percibido no son equivalentes

En las últimas décadas hemos experimentado profundos y rápidos cambios de carácter tecnológico, económico y social, algo que, en parte, ha propiciado el surgimiento de una variedad de riesgos coligados a la alimentación, la tecnología, las finanzas, la industria, la naturaleza, la exclusión social o la violencia política, por citar algunos ámbitos. En este contexto, algunos autores como Ullrich Beck $(1998,2002)$ han definido a la sociedad moderna como la sociedad del riesgo, caracterizada por la complejidad, la incertidumbre y la ambigüedad. Además, la percepción del riesgo está basada en complejos sistemas de creencias, emociones, valores e ideales, modulado todo ello por las nuevas tecnologías de la información y la comunicación. O en otras palabras: no existe riesgo sin construcción social del mismo (Sjöberg, 2000; Slovic, 1987). Sin embargo, en ocasiones, la distancia entre riesgo real y riesgo percibido es considerable. Un ejemplo paradigmático podría ser la consideración del riesgo vinculado a la epidemia de ébola en el contexto de nuestras sociedades occidentales. Una percepción del riesgo real excesivamente distorsionada puede convertirse también, a día de hoy, en un problema. Y es que, epidemiológicamente, el "virus del miedo" (psicológicamente estimable utilizando indicadores de estrés o ansiedad) es el que más rápido se propaga, paralizándonos o desencadenando respuestas de activación desproporcionadas. No lo olvidemos: las percepciones, las creencias y las emociones asociadas son "contagiosas"; para lo positivo y para lo negativo (Engert, Plessow, Miller, Kirschbaum y Singer, 2014; Hatfield, Cacioppo y Rapson, 1994). Por ello, aunque en ocasiones no esté exento de dificultad, es fundamental concentrar nuestra influencia en ocuparnos del problema en sí y, reducir, en la medida de lo posible, una preocupación poco adaptativa sobre el mismo.

\section{Segundo. Contención, juicio y prudencia en la comunicación}

Sin entrar a describir los errores cometidos en la comunicación relativa al caso y a otros similares, conviene recordar que: (1) es fundamental tener un único portavoz (y elegirlo bien) para transmitir la información oficial, algo que propicia la unidad de criterios, dificulta la propagación de rumores y la distorsión informativa y facilita el trabajo de los profesionales de los medios de comunicación social; (2) en caso de que hubiera más de un portavoz, nunca debiera haber contradicciones en los mensajes transmitidos por cada uno de ellos; (3) priorizar la claridad y veracidad de los mensajes, procurando que sean asequibles para la población general. Datos confusos, ambigüedades, tecnicismos y mensajes densos pueden inocular dudas e impedir la compresión de la información realmente útil en términos de salud pública; y, por último, (4) cuidar la puesta en escena: "tiempos, formas y no decir barbaridades". Exabruptos desafortunados e imprudentes por parte de los responsables directos en la gestión de la crisis, pero también de otros actores secundarios del escenario, sólo van a formar parte del problema. Nunca de la solución.

\section{Tercero. El todo es más que la suma de las partes}

Es habitual distinguir tres perspectivas en gestión de riesgos: ciencia, precaución y deliberación (Klinke y Renn, 2002; Renn y Klinke, 2004). En primer lugar, la gestión basada en la ciencia se fundamenta en la implementación de los criterios científicos existentes con el fin de describir, explicar y predecir, para de esta forma, poder intervenir sobre un fenómeno (por ejemplo, conseguir el desarrollo experimental y la administración de una vacuna eficaz). En segundo lugar, la gestión basada en el principio de precaución pretende encontrar un equilibrio entre el déficit y el exceso de cautela. Esto supone la adopción de medidas protectoras ante sospechas fundadas de que existe un riesgo sin que aún se disponga de evidencia científica concluyente al respecto. Se suele aplicar en aquellos 
acontecimientos que no conocemos totalmente (una decisión basada en este principio sería el sacrificio de la mascota de la auxiliar de enfermería contagiada en el caso que estamos tratando). En tercer lugar, la gestión basada en la deliberación puede ser caracterizada como la promoción de tácticas que tengan en cuenta los múltiples factores implicados, así como los valores (y contravalores) de las partes. Procedimientos como la mediación y la participación directa de los ciudadanos con el fin de llegar a consensos podrían incluirse en esta categoría (los debates surgidos sobre la conveniencia de repatriar a los misioneros contagiados para atenderlos en España serían un ejemplo). Pues bien, poner la lupa en una única perspectiva nos va a ofrecer una visión reduccionista del problema (y de sus potenciales soluciones) y va a entorpecer representar la globalidad. Y es que, aunque se ha avanzado considerablemente en un breve período de tiempo, las evidencias científicas sobre la eficacia de las diferentes vacunas contra el ébola son todavía escasas. La adopción de medidas protectoras excesivamente conservadoras puede tener efectos más perjudiciales que beneficiosos en términos de alarmismo (falsos positivos), ya que una percepción distorsionada del riesgo, generalizada en la ciudadanía, podría provocar colapsos en urgencias o el aislamiento de personas que, por ejemplo, simplemente padecen gripe estacional o un resfriado común. Y la deliberación en la gestión de riesgos es fundamental en un Estado de Derecho; pero siempre que no se negocien los principios de nuestra convivencia y que no se comprometan los criterios técnicos elementales. En definitiva, las tres perspectivas expuestas (ciencia, precaución y deliberación) son importantes y desafían un campo de verdad. Se requiere, por tanto, mente abierta para integrarlas.

\section{Cuarto. Pensamiento divergente para anticiparnos}

Siguiendo el hilo conductor de lo expuesto anteriormente, desde un enfoque estratégico y en ciertos foros, debiéramos "prepararnos para lo peor", elaborando y poniendo a prueba hipótesis imposibles (Lowenthal, 1993; Taleb, 2007). Esta idea enfatiza la importancia de anticiparse a los acontecimientos que pueden constituirse en amenazas reales, incluso aunque sean altamente improbables; algo que implica simular situaciones imaginarias, inverosímiles o extremas, en las que la suerte de los acontecimientos pudiera ser tan inesperada que sorprendiera a las autoridades políticas y sanitarias, y por extensión, a los ciudadanos. Aunque es difícil estimar y predecir todos los posibles de corte futurible asociados a la crisis del ébola, actuaciones destinadas a la anticipación y que resuelvan nuestra necesidad de cierre cognitivo $\mathrm{y}$, por tanto, de certidumbre, pueden ser positivas (Noda, 2016). La necesidad de cierre cognitivo es una variable psicológica muy relacionada con la motivación de las personas a pensar en categorías dicotómicas extremas, realizando una función epistémica fundamental al dar por finalizada la secuencia de búsqueda de información y de contrastación de hipótesis (Kruglanski, 2004). Asimismo, sabemos que dicha variable está modulada de forma potente por factores ambientales tales como la resistencia psicológica, presión temporal, nivel de cualificación, percepción de amenaza, fatiga o demandas extremas. Habría que apostar por trabajar en el desarrollo de protocolos, la coordinación interinstitucional, el alcance de acuerdos internacionales, la ejecución de simulacros y los abordajes preventivos innovadores. Una vez que los problemas aparecen, el tiempo será un factor que juegue en contra.

\section{Quinto. Formación técnica (y psicológica) para los profesionales}

Uno de los retos prioritarios para contrarrestar el ébola es mejorar la formación (que no la simple información) destinada a los profesionales sanitarios. Con respecto a la formación técnica, desde la Psicología se han propuesto numerosas técnicas de utilidad para optimizar la adquisición de las competencias necesarias para atender a los enfermos, tales como la instrucción, el modelado, el ensayo, la retroalimentación, el refuerzo y la generalización. No se trata simplemente de aprender "cómo ponerse y quitarse un traje" o el manejo conductual y ambiental básico para minimizar el riesgo de contagio (que por otra parte está vinculado a vectores psicosociales y a la transmisión persona a persona), sino que es fundamental recrear situaciones reales, con sus oportunos planes de contingencia, que pueden surgir en el entorno hospitalario del paciente (éste último, en ocasiones, potencialmente agitado) o en contextos eventuales de intervención (aeropuertos, fronteras, ciudades, medios de transporte masivo como barcos o aviones, etc.). El entrenamiento en escenarios contextualizados facilitará la transferencia y generalización del conocimiento de la virtualidad a la realidad. Además, teniendo en cuenta los niveles de estrés a los que pueden verse sometidos los profesionales implicados, es también decisiva la formación psicológica para su afrontamiento. En ese sentido, algunas técnicas y habilidades que deben formar entrenarse para que formen parte del repertorio de los profesionales intervinientes son el apoyo social, la resolución de problemas, la toma de decisiones, la reestructuración cognitiva, el control emocional, diferentes estrategias de influencia, la intervención basada en la acción automatizada o la relajación.

\section{Sexto. Asistencia psicológica a profesionales y víctimas}

La crítica constructiva siempre es necesaria. Pero culpabilizar, generalmente de forma injusta, a profesionales comprometidos que ofrecen lo mejor de sí mismos no es una buena opción. A los profesionales hay que valorarlos y visibilizar el servicio público que prestan. Merecen nuestro reconocimiento y respeto, mucho más teniendo en cuenta que podrían estar poniendo en riesgo real su propia salud. Como hemos expuesto, es más que previsible que aquellos profesionales sanitarios directamente implicados en la atención a enfermos de ébola se vean sometidos a un elevado nivel de estrés que repercuta 
en su estado físico y anímico. Por ello, sería positivo poner a su disposición unidades de asistencia psicológica temprana por parte de profesionales especializados en la aplicación de estrategias de intervención en crisis, principalmente para ofrecer apoyo tras incidentes o situaciones complejas y difíciles de abordar. Además, habría que capacitar al personal sanitario para prestar primeros auxilios psicológicos a compañeros que lo necesiten en contextos críticos de intervención. Con respecto a las víctimas también será imprescindible el apoyo psicológico para optimizar su ajuste anímico y, así, su salud mental, debido, entre otras cosas, al debilitamiento físico extremo (intrínseco a la enfermedad) que van a sufrir, al previsible aislamiento al que van a ser sometidos (para evitar la propagación) y al estigma al que pueden verse expuestos posteriormente (en el supuesto de que superen la infección vírica). Abordar de forma temprana los moderadores y moduladores del estrés en profesionales y víctimas será un objetivo ineludible de intervención a corto, medio y largo plazo; y favorecerá que no aparezcan, o que aparezcan en menor grado, otros trastornos más graves y susceptibles de tornarse en crónicos como, por ejemplo, el estrés postraumático.

\section{Séptimo. Arquitectura de una sociedad resiliente}

Es preciso atender no sólo las amenazas y debilidades del sistema, sino también sus fortalezas y oportunidades (Leaning y Guha-Sapir, 2013; Mitchell, 2007; Norris, Stevens, Pfefferbaum, Wyche y Pfefferbaum, 2008). Quizás, la dificultad para asumir ciertos costes de respuesta y una elevada intolerancia a la incertidumbre podrían considerarse dos puntos débiles de nuestra sociedad. Sin embargo, si nos mantenemos unidos, la sinergia que se puede generar está fuera de toda duda. Ya lo hemos demostrado en otras ocasiones. $\mathrm{Y}$ nuevos acontecimientos van a seguir poniendo a prueba nuestra capacidad de resistencia. Por ese motivo, hay que seguir incidiendo en la necesidad de robustecer los recursos de afrontamiento de las instituciones y la sociedad civil, con el fin de reforzar las respuestas psicosociales positivas (liderazgo positivo, respeto, cohesión, valores democráticos, solidaridad, cooperación) e inhibir las respuestas psicosociales negativas (amenaza, prejuicio, discriminación, culpa, miedo, desconfianza). Con el fin de dar respuestas integrales, habría que hacer partícipes a los profesionales e instituciones sanitarias, pero también contar con la complicidad de los medios de comunicación social y la colaboración proactiva de toda la sociedad: Fuerzas y Cuerpos de Seguridad del Estado, Fuerzas Armadas, dispositivos de intervención social, sistema educativo, tejido empresarial, asociaciones y organizaciones sin ánimo de lucro. Teniendo en cuenta el potencial de movilización que una crisis sanitaria de este tipo podría llegar a tener, habría que hacer partícipes a los profesionales e instituciones sanitarias, pero también contar con la complicidad de los medios de comunicación social y la colaboración proactiva de toda la sociedad: Fuerzas y Cuerpos de Seguridad del Estado, Fuerzas Armadas, dispositivos de intervención social, sistema educativo, tejido empresarial, asociaciones y organizaciones sin ánimo de lucro. Todos somos necesarios, en la unión nos haremos fuertes.

\section{Conclusiones}

Desde los albores de la Humanidad, las situaciones extremas y críticas nos han puesto a prueba como especie, y lo van a seguir haciendo. Catástrofes naturales, accidentes, violencia política, epidemias y eventos vitales traumáticos de diferente tipo han existido siempre y seguirán existiendo. Ante estos escenarios, el papel de la Psicología como ciencia es fundamental, y entre sus potenciales aplicaciones prácticas estarían los avances relativos al conocimiento de los factores moduladores del estrés, la comunicación de malas noticias, el manejo conductual en diferentes contextos, los primeros auxilios psicológicos o la evaluación e intervención ante diferentes tipos de riesgos.

En el presente artículo se ha realizado una propuesta de siete principios de intervención en el abordaje de la crisis asociada al ébola, utilizando para ello las lecciones aprendidas de lo que fue el primer caso de contagio en Europa, y por ende, en nuestro Estado, a principios de octubre de 2014. No obstante, los argumentos expuestos debieran ser entendidos como un marco de utilidad transferible a otro tipo de escenarios de intervención en crisis y emergencias, especialmente ante epidemias asociadas a enfermedades como la malaria, el dengue, el chikunguña o el zika.

A lo largo de los principios expuestos se enfatiza el carácter biopsicosocial de potenciales intervenciones, resaltando un enfoque integral y participativo de la concepción de salud y enfermedad, y asumiendo que tanto los aspectos biológicos, los psicológicos como los factores sociales desempeñan un papel determinante y deben ser atendidos. Asimismo, se ha enfatizado el papel de la percepción, la comunicación social, la anticipación a diferentes futuribles o la importancia de la intervención psicológica temprana para evitar trastornos más graves como el estrés postraumático. Pero sobre todo, la relevancia de la formación previa para dotar a las personas y a las comunidades de los recursos personales de afrontamiento para minimizar posibles crisis $\mathrm{y}$, en definitiva, ser más resistentes ante la adversidad.

\section{Referencias}

1. Beck, U. (1998). La sociedad del riesgo: hacia una nueva modernidad. Barcelona: Paidós.

2. Beck, U. (2002). La sociedad del riesgo global. Madrid: Siglo XXI.

3. Engert, V., Plessow, F., Miller, R., Kirschbaum, C. y Singer, T. (2014). Cortisol increase in empathic stress is modulated by emotional closeness and observation modality. Psychoneuroendocrinology, 45, 192-201. http://dx.doi. org/10.1016/j.psyneuen.2014.04.005

4. Hatfield, E., Cacioppo, J.T. y Rapson, R.L. (1994). Emo- 
tional contagion. Cambridge: Cambridge University Press.

5. Klinke, A. y Renn, O. (2002). A new approach to risk evaluation and management: Risk-based, precaution-based, and discourse-based strategies. Risk Analysis, 22, 1071-1094. http://dx.doi.org/10.1111/1539-6924.00274

6. Kruglanski, A.W. (2004). The psychology of closed mindedness. New York, NY: Psychology Press.

7. Leaning J. y Guha-Sapir D. (2013). Natural disasters, armed conflict, and public health. The New England Journal of Medicine, 369, 1836-1842. http://dx.doi.org/10.1056/ NEJMra1109877

8. Lowenthal, M. (1993). Intelligence epistemology: Dealing with the unbelievable. International Journal of Intelligence and Counterintelligence, 6, 319-325. http://dx.doi. org/10.1080/08850609308435222

9. Mitchell, J.T. (2007). Innovative, precise and descriptive terms for group crisis support services: A United Nations initiative. International Journal of Emergency Mental Health, 9, 247-252.

10. Noda, M. (2016). Does affective forecasting change motivation for disaster preparedness? Motivation one month after a hypothetical earthquake. Revista de Psicología Social: International Journal of Social Psychology, 31, 109-136. http://dx.doi.org/10.1080/02134748.2015.1101315
11. Norris, F.H., Stevens, S.P., Pfefferbaum, B., Wyche, K.F. y Pfefferbaum, R.L. (2008). Community resilience as a metaphor, theory, set of capacities, and strategy for disaster readiness. American Journal of Community Psychology, 41, 127-150. http://dx.doi.org/10.1007/s10464-007-9156-6

12. Organización Mundial de la Salud (OMS). (2014). Enfermedad por el virus del Ebola. Nota descriptiva 103, abril de 2014.

13. Renn, O. y Klinke, A. (2004). Systemic risks: A new challenge for risk management. European Molecular Biology Organization, 5, 41-46. http://dx.doi.org/10.1038/ sj.embor.7400227

14. Sjöberg, L. (2000). Factors in risk perception. Risk Analysis, 20, 1-11. http://dx.doi.org/10.1111/0272-4332.00001

15. Slovic, P. (1987). Perception of risk. Science, 236, 280-285. http://dx.doi.org/10.1126/science.3563507

16. Taleb, N.C. (2007). The black swan. The Impact of highly improbable. New York: Random House.

Fecha de recepción: 26 de octubre, 2015

Fecha de recepción de la versión modificada: 26 de abril, 2016

Fecha de aceptación: 6 de mayo, 2016 